\title{
NOTES ON BOOKS
}

Its graphic style and practical character placed $\mathrm{Dr}$ Robert Hutchison's Lectures on Diseases of Children (Edward Arnold) in the forefront of works of its class when it first appeared. The characteristics which secured the success of the earlier editions are equally apparent in this, the fourth. The text has been carefully revised, and a useful chapter on fevers of obscure origin has been added. It is certainly one of the most useful text-books that a student or practitioner can possess. The illustrations are excellent, and well bring out the clinical features of the diseases portrayed.

Much that was originally written by Sir James F. Goodhart thirtyfive years ago remains true to-day, but this eleventh edition of his work, The Diseases of Children (J. \& A. Churchill), edited by Dr Still, includes the many fresh advances which have been made in the science of Pediatrics. Thus all the latest theories in regard to the chemical pathology of the nutritional disorders of infancy are fully discussed, and many illustrations have been added.

Under the rather misleading title Infant Education (London: Henry Kimpton, r920, 6s. net), Dr Eric Pritchard has published a series of lectures to mothers on the care of infants. The Child Welfare movement has produced a considerable number of books of this type; they are quite harmless, inasmuch as they say nothing valuable that every sensible mother does not know, and we suppose they must be useful to the ignorant and foolish. But one wonders, sometimes, if they are really worth while.

The seventh edition of Surgical Pathology and Morbid Anatomy, by Sir Anthony A. Bowlby and Sir Frederick W. Andrewes (J. \& A. Churchill, price 305 . net), contains new chapters on Gas Gangrene, Shock, and Tetanus. In addition the whole text has been brought thoroughly up to date. Many new illustrations have been added and the old ones have been redrawn and are reproduced on a larger scale than formerly. The scope of the text-book is such as to make it useful for students rather than for graduates.

Dr Marsh Pitzman has endeavoured in The Fundamentals of Human Anatomy (Henry Kimpton, price $24 \mathrm{~s}$. net) to give the student an understandable account of human anatomy, without burdening his memory with an excess of detail. He tries also to indicate the practical bearing of anatomical facts as well as to take note of sidelights from physiology, embryology, histology, and other borderland subjects. The book is arranged also so that it may be used as a 


\section{Notes on Books}

dissecting manual. To attempt to accomplish so much in the compass of some $35^{\circ}$ pages is certainly ambitious.

The intentions of the author are to be commended, but it is to be feared he has attempted too much in so small a space. Descriptions as a rule are too brief to be of any use to the student. A structure like the ulnar nerve is disposed of in half a dozen lines, and with the remark that "in general it tends to supply the medial half of the hand and fingers," individual muscles in the hand being ignored. It is difficult to see how the book can hold a useful place in the teaching of students.

The Synopsis of Surgery by Ivor Back and A. Tudor Edwards (J. \& A. Churchill, price ${ }_{5} 5 \mathrm{~s}$. net) takes its place in that already long list of books which have been written to enable the "less industrious majority" of students to revise their work for the final examination. The synopsis covers the whole of General and Regional Surgery, with specially contributed sections on Venereal Diseases and Diseases of Ear, Nose, and Throat. Very short descriptions of the standard amputations are also included. If the student will realise that this volume is not intended to replace the larger text-books, no doubt it will have a sphere of usefulness.

A Guide to Anatomy for Students of Medical Gymnastics-Massage and Medical Electricity, by E. D. Ewart (H. K. Lewis \& Co., I6s. net), is written by one who has knowledge both as a teacher and an examiner of the requirements of Students of Medical Gymnastics. The text is concise and the diagrams are extremely clear and well charted.

1)r Rixon and Dr Matthew's little brochure on Anxiety Hysteria (Lewis, London, 1920) will be found very useful by those who have to deal with this troublesome class of case. It is simple, sane, and sensible, and can be recommended.

Dr Arthur Hurst has republished in book form the Cromian Lectures delivered in 1920, under the title of The Psychology of the Special Senses (Hodder \& Stoughton, London, 12s. 6d. net). Dr Hurst's work at Seale Hayne is well known to all interested in psychology, and many will be glad to have the lectures in this compact form.

A sixth edition of diseases of the Lungs and Pleurce by Sir R. Douglas Powell and P. Horton Smith Hartley (H. K. Lewis \& Co., Ltd., price 42S.) has appeared. New chapters have been added on gunshot wounds of the chest, chylothorax, massive collapse of the lung, sporotrichosis and artificial pneumothorax, and the newer work on the bacteriology of pneumonia is included. Irritant gas-poisoning is briefly mentioned, but no reference is made to ultimate results. 


\section{Notes on Books}

In the section on pulmonary tuberculosis a timely warning is given about the emigration laws in relation to this disease. Hilum tuberculosis is considered briefly, and the authors think it is "an unnecessary addition to the nomenclature." The diagnostic value of X-rays in pulmonary tuberculosis is considered by the authors to be very limited.

Physical Signs in the Chest and Abdomen, by A. J. Jex-Blake (J. \& A. Churchill, price 9s. 6d.) is primarily of value to students, and offers a good general introduction to the clinical methods commonly employed in the examination of the chest and abdomen. The larger part of the work is devoted to the chest, and only the commoner diseases are considered. There are some good diagrams illustrating the graphic representation of physical signs.

Dr Einhorn in The Duodenal Tube (W. B. Saunders Company, price I3s. net) has given a concise yet complete account of the duodenal tube and its possibilities. He reviews the history of the development of this method of diagnosis and treatment, compares the various instruments, and outlines their advantages and disadvantages. In the chapter on the examination and diagnostic importance of the duodenal contents many points of practical importance are dealt with, and the use of this instrument as a therapeutic agent is briefly reviewed. It is a valuable monograph for all who are interested in the diagnosis and treatment of duodenal conditions.

Text-Book of Tracheo-Bronchoscopy, by Sanitätstrat Dr M. Mann, Dresden-Friedrichstadt (John Bale, Sons, \& Danielsson, Ltd., price 3 Is. 6d.) is the translation by Mr A. R. Moodie of a book which appeared in rgi4. According to the translator, no advances of importance have been made either as regards the method itself or in its application. The anatomy of the parts gets scanty consideration, but a considerable portion is devoted to the history of the specialty and armamentarium. Cases are quoted describing practically every variety of foreign body that has been encountered. The book contains practically all the cases published up to r9i4. Chapters on the diseases of the Tracheo-Bronchial tree, with notes as to their treatment by the direct method, are of considerable interest.

Surgical Aspects of Dysentery, by Zackary Cope, F.R.C.S. (Henry Frowde and Hodder \& Stoughton, price r2s. 6d. net). The large number of men who served in tropical climates during the war, and who with few exceptions suffered from dysentery, has made an acquaintance with the late manifestations of this disease a necessity to all medical men in this country. The author from a wide experience gained in Mesopotamia has produced a monograph which, while dealing with the surgical aspects of the disease, includes an excellent

VOL. XXVI. NO. VI. 


\section{Notes on Books}

account of the pathology of the condition in its various stages. The benefits to be derived from appendicostomy and cæcostomy in the chronic ulcerative types of dysentery are very clearly demonstrated, and the indications for one or other of these operations well defined. Contrary to usual belief strictures of the colon and rectum following dysentery are shown to be very rare indeed. The chapter dealing with amœbic hepatitis and liver abscess are tersely written and beautifully illustrated, and form the feature of an admirable book which can be confidently recommended to all interested in the subject, and particularly to those who are to practise in tropical countries.

The Medical Examination of Airmen, by Drs Maublanc and Ratié, of the Châtres School of Flying (John Bale, Sons, \& Danielsson, Ltd.), confirms the opinion that we have held for some time that in no small proportion of the crashes said to be due to "engine trouble" it is the human engine which has "missed." By carefully carrying out the routine detailed in the above work, and especially in regard to fatigued or even apparently healthy pilots, the human element contributing to these often preventable disasters can be reduced to a minimum. The translation from the French is by Norman Bale.

Within four years another, a seventh, edition of Dr Robert Jardine's Practical Text-book of Midwifery for Nurses (Henry Kimpton, 1920, price $7 \mathrm{~s}$. 6d. net) has been called for. The text has been brought up to date, and one or two illustrations have been added. This book deservedly continues to be in great demand by nurses training for the Central Midwives Board Examination, and no more useful guide could be found for them. It also proves a most reliable help to junior students commencing the subject of Obstetrics.

Nitrous Oxide Oxygen Analgesia and Ancesthesia in Normal Labour and Operative Obstetrics is the title of a monograph published by the National Anæsthesia Research Society. A great many testimonies have been gathered together here in favour of nitrous oxide oxygen anæsthesia ; but one quotes, with a little satisfaction, the sentence "Nitrous oxide is no panacea for poor obstetrics," as a word or two of permanent value.

A Consulting Surgeon in the Near East (Christophers) is a record of Colonel A. H. Tubby's experiences as a consulting surgeon with the Armies of the Middle East from July I9I 5 until after the Armistice. $\mathrm{He}$ deals with those anxious days for the medical service when they had to evacuate their wounded from the shell-swept beaches at Helles, Anzac, and Suvla, direct to the hospital ships, and he has good words to say for the part played by the "Black Ships," transports and liners commandeered as hospital transports. The book also contains 


\section{Notes on Books}

particulars of Colonel Tubby's service at Alexandria with the Egyptian Expeditionary Force. It is brimful of interest, and will prove a valuable addition to the medical history of the war from a personal standpoint.

The best part of Dr Crow's Pyorrheea Alveolaris in its Clinical Aspect (Baillière, Tindall, \& Cox, price 6s. net) is the foreword by Sir Frank Colyer. The book itself contains some false statements and many unjustifiable conclusions, but the object of the author is a good one, viz., "to emphasise once again the overwhelming importance of pyorrhœa alveolaris in the causation of many of the diseases and minor complaints met with in medical practice."

In The Auld Doctor (Constable \& Co., price 3s. 6d.) Dr David Rorie has put within reach of the general reader a selection of the poems and songs in Scots with which he has so often amused and delighted his medical friends at social gatherings. They will appeal most strongly to men of the North, who can dispense with the glossary provided for their less favoured brethren.

Six Papers by Lord Lister is the first instalment of the new Medical Classics Series to be issued by Messrs John Bale, Sons, \& Danielsson, Ltd., under the general editorship of Dr Charles Singer. Sir Rickman J. Godlee contributes an admirable short biography of Lister, and explanatory notes to the six papers selected for reproduction. These include the historical papers on Inflammation, Anæsthetics, the treatment of Compound Fractures, Antiseptic Surgery, and Fermentation. Those who have not ready access to the Collected Papers will welcome this judicious selection of Lister's writings. The price is ros.

A fifth edition of Mr Hey Groves' Synopsis of Surgery (John Wright \& Sons, Ltd., price I $7 \mathrm{~s}$. 6d.) has appeared, which shows that this class of work is still in demand.

Medical Notes by Sir Thomas Horder (Henry Frowde and Hodder \& Stoughton, price 6s.) is a series of somewhat obvious aphorisms.

Dr Wm. Sharp has detailed his extensive experience of head injuries in a large volume entitled Diagnosis and Treatment of Brain Injuries (J. B. Lippincott Company, price 35s.). Considerable space is devoted to injuries of the brain in new-born babies, which is perhaps the most interesting section of the work.

The handsome Centenary volume of Charles Griffin \& Co., Ltd. (I 820-1920), constitutes a record of which this famous publishing house may well be proud. The contributors include such well-known names as those of Sir W. S. Abell, Professor Hudson Beare, and Professor W. Gowland, and there is a preface by Lord Moulton. The place which 


\section{Notes on Books}

Messrs Charles Griffin hold as publishers of scientific and technical work is very high, and English science and technology are greatly in their debt. We venture cordially to congratulate the firm on having been able to produce such a striking tale of its activities for its centenary volume.

Women as Army Surgeons by Flora Murray (Hodder \& Stoughton), gives a most interesting description of the doings of this band of women who so successfully organised and ran a large military hospital for over four years.

The Principles and Practice of Medicine, by Sir William Osler and Thomas M'Crae (D. Appleton \& Co., price 3 os. net), now appears in its ninth edition, which has been thoroughly revised and brought up-to-date. There is a great deal of new material, as shown by the sections on Paratyphoid Fever, Focal Infection, Trench Fever, Acidosis, Diverticulitis, Infectious Jaundice, Hæmothorax, Mediastinitis, Epidemic Encephalitis, etc. Many of the other parts have been rewritten and recent work added. The book is designed for the use of the practitioner and the student. The former will find it a help in his practice, the latter that it is easily read, and the arrangement of the sections helpful to him.

Essentials of Medicine, by C. P. Emerson, M.D. (Lippincott, price r2s. 6d. net), is a manual of medicine intended for nurses, which might also with advantage be read by medical students before beginning the study of clinical medicine. The various systems and their diseases are considered in order, as in a more elaborate text-book, and the descriptions are throughout expressed in clear, non-technical language. The diagrams are very helpful in the explanation of pathological conditions in the organs concerned. The principles of treatment in each disease are indicated, but not given in detail. The book is well planned and written for the object in view.

Drs Sillar and Lambie have reduced the essentials of materia medica to pamphlet form. For Selected Materia Medica (James Thin Edinburgh, 2s. 6d. net) generations of students will rise and call the authors blessed, and unless we are much mistaken the little book will have a large and steady sale.

It is unnecessary to do more than note the appearance in book form of Rows and Orr's Functional Mental Illnesses (Oliver and Boyd 1920, 3s. 6d. net) which has already appeared in extenso in the pages of this journal.

The rat, according to Prof. Shipley, shares with certain species of insects the distinction of being man's greatest enemy on this earth. Whether this be so or not, rats are disagreeable vermin, and better away, wherefore Mr Dewberry's monograph on The Destruction and 


\section{Notes on Books}

Prevention of Rats (John Bale, Sons \& Danielsson, Ltd., 1920) deserves circulation among farmers and property owners generally. It may be described as a Rat-catcher's Gospel, and costs a modest florin.

The third edition of Col. Blackman's Military Sanitation (John Bale, Sons and Danielsson, Ltd., price Ios. 6d. net) has been largely rewritten to incorporate the numerous lessons which have been learnt as a result of war experience. All aspects of this important subject are fully discussed and an appendix is added giving in tabulated form the Communicable Diseases of Soldiers, their chief characteristics, and preventive treatment.

Lectures on Surgery for Nurses, by Alan H. Todd (Edward Arnold, price $7 \mathrm{~s}$. 6d.), is based on a course of lectures delivered to probationers at Guy's Hospital, and gives concisely and simply the essential facts of Pathology and Surgery. The illustrations are excellent. Nurses commencing their training should find this book of considerable value.

A Text-book of Pharmacology and Medical Treatment for Nurses, by Dr Fortescue Brickdale (Henry Frowde and Hodder \& Stoughton, price $28 \mathrm{~s}$.), is a well-prepared handsome volume whose production is creditable to the publishers. The author has assumed a difficult task, as he has had to present a highly technical subject to an almost lay clientele. He has, therefore, had to adopt his terminology and descriptions accordingly, and to limit the amount and range of information imported. He has succeeded in presenting his subject clearly, and appears to have produced a work which ought to be of use to nurses as a book of reference. It will appeal more to senior nurses than to beginners, and its price will probably tend to limit its circulation. The illustrations add greatly to its value and are well chosen. The author has very wisely devoted most space to the therapeutic part of his subject, and has useful chapters on Organotherapy and Serum therapy. His explanations of the rationale of treatment will enable nurses to carry out their work with a better knowledge of what they are doing.

Obstetrics, Normal and Operative, by George Peaslee Shears, B.S., M.D. (third edition, revised by Philip F. Williams, J. B. Lippincott Company, price 35 s. net), can be confidently recommended as giving a clear account of the present-day teaching of obstetrics. Throughout it bears the impress of the writer's individual experience. The main outlines of the literature are given, and in matters still under discussion a fair balance between opposing views is maintained. The illustrations are good. A very large number are borrowed from wellknown continental and other text-books. The book is one which is suitable both for students and practitioners.

vol. XXVI. NO. VI. 


\section{Notes on Books}

That a second edition of the Elements of Hygiene and Public Health, by J. P. Medi (Butterworth \& Co., price r2s. net), should have been found necessary, proves that his book has supplied a want among Indian medical students. The teaching is sound and simple. The section dealing with Village Sanitation is well done, and a like compliment can be paid to the chapter dealing with Tropical Diseases. There is no fear of Preventive Medicine in India if this handy volume is carefully studied by the students and medical practitioners, for whom it is intended.

The call for a sixth edition of Professor M'Murrich's Development of the Human Body (Henry Kimpton, price r8s. net) is eloquent testimony to its popularity and success. In the present volume several chapters have been recast so as to enable the author to include references to important recent work without overloading the book and making it too large. This is still the most satisfactory small book on a difficult subject with which we are familiar.

Notes on Midwifery, by J. M. Munro Kerr, M.D., and Jas. Hendry, M.A., B.Sc., M.B. (second edition, Maclehose, Jackson \& Co., price ros. 6d. net), is a synopsis in note form of Professor Munro Kerr's lectures to his students in Glasgow. It is, therefore, superfluous to say that the subject-matter is beyond criticism. It is printed on one side of the page only, so that the student can fill out the print from the lecture as delivered. It will be useful to students preparing for examinations, and to teachers who wish to revise a subject rapidly. There are numerous textual errors of an obvious nature.

In the volume of the "Students' Synopsis Series" devoted to Physiology, Dr Ffrancon Roberts (J. \& A. Churchill) has most successfully condensed the essentials of the subject within a compass suitable for the student. We specially commend the work to the final year student who desires to revise his physiology as an aid to his study of medicine and surgery.

Dr Ibbotson's Atlas of the Sensory Cutaneous Nerves (Scientific Press) is a handy means of refreshing the memory on points which can neither be carried continuously nor entirely forgotten.

Sir Charles A. Ballance has reprinted his Bradshaw Lecture on the Surgery of the Heart (Macmillan \& Co., Ltd.). It contains a record of the subject from the earliest times to the present and is abundantly documented.

The life-story of Elsie Inglis has been retold by Lady Frances Balfour in the "Young Citizen Series" (British Periodicals, Ltd.), and by her sister, Eva Shaw M'Laren, in the "Pioneers of Progress Series" (S.P.C.K.). It is a story that cannot be too widely diffused as an example and an inspiration to the young. 


\section{Notes on Books}

When Professor Schmeiden's Course of Operative Surgery (Baillière, Tindall \& Cox) first appeared ten years ago, we formed a high opinion of it, and we find no reason to modify our opinion. after a study of the second edition, which is now before us. It has been prepared in collaboration with $\mathrm{Mr}$ Arthur Turnbull, and has a foreword by Professor August Bier. The illustrations are admirable.

The Transactions of the American Surgical Association, vol. xxxvii., I9r9 (Philadelphia, W. J. Doran), is largely taken up with surgical problems connected with military surgery, but following the lead given by Dr Pilcher in his presidential address, an attempt is made by some of the writers to apply the lessons learned in warfare to the needs of civilian practice. With the lapse of time this is the aspect of military surgery that has most interest for the civil surgeon, and from this point of view we can commend this collection of essays.

George Miller Sternberg: A Biography, by his wife, Martha L. Sternberg (American Medical Association), is of general interest as dealing with the career of a man who was intimately concerned in some of the most important phases of American history, the Civil War, the Indian Wars, and the Spanish-American War. Apart from this, it has a great professional interest in that General Sternberg was Surgeon-General of the U.S. Army Medical Department when the Yellow Fever Commission was appointed in 1900. The important work of that Commission in elucidating the transmission of the disease, from which arose the far-reaching means for its eradication, is described in correspondence published in this volume. It forms a very readable record of an assiduous worker and attractive personality.

American Medical Biographies, by H. A. Kelly, M.D., and W. L. Burrage, M.D. (Norman, Remington Company), includes over I 900 biographies of medical men who have attained a measure of distinction in the United States and Canada during the past three hundred years. It does not include names of those still living in 1918. The work appears to have been carried out with great care and success by a large staff of contributors. Naturally its general interest is greater on the western side of the Atlantic, but for everyone concerned with the development of medical science, practice and teaching, it forms an invaluable work of reference. 